\title{
Effects of Quinizarin and Five Synthesized Derivatives on Fifth Larval Instar Midgut Ecdysone 20-Monooxygenase Activity of the Tobacco Hornworm Manduca sexta
}

\author{
Christopher A. Drummond, ${ }^{1,2}$ Maria Teresa Molina, ${ }^{3}$ Sandra Taliansky, ${ }^{3}$ \\ Carl R. Breidenbach, ${ }^{2}$ and Carmen F. Fioravanti ${ }^{2}$ \\ ${ }^{1}$ Department of Medicine, University of Toledo Medical School, 3000 Arlington Avenue, 202 Health Education Building, \\ Mail Stop 1025, Toledo, OH 43614, USA \\ ${ }^{2}$ Department of Biological Sciences, Bowling Green State University, Bowling Green, OH 43403, USA \\ ${ }^{3}$ Instituto de Quimica Medica (IQM-CSIC), Juan de la Cierva 3, 28006 Madrid, Spain
}

Correspondence should be addressed to Christopher A. Drummond; christopher.drummond@utoledo.edu

Received 28 July 2014; Accepted 7 October 2014; Published 21 October 2014

Academic Editor: Greg Demas

Copyright (c) 2014 Christopher A. Drummond et al. This is an open access article distributed under the Creative Commons Attribution License, which permits unrestricted use, distribution, and reproduction in any medium, provided the original work is properly cited.

\begin{abstract}
The plant allelochemical, quinizarin (1,4-dihydroxy-9,10-anthraquinone), and five anthraquinones that were synthesized from quinizarin, namely, 1,4-anthraquinone; 2-hydroxy-1,4-anthraquinone; 2-methoxy-1,4-anthraquinone; 9-hydroxy-1,4anthraquinone; and 9-methoxy-1,4-anthraquinone, were assessed as to their effects on the essential, P450-dependent ecdysone 20-monooxygenase system of the insect model Manduca sexta (tobacco hornworm). This steroid hydroxylase converts the arthropod molting hormone, ecdysone, to the physiologically required 20-hydroxyecdysone form. M. sexta fifth larval instar midgut homogenates were incubated with increasing concentrations $\left(10^{-8}\right.$ to $\left.10^{-3} \mathrm{M}\right)$ of each of the six anthraquinones followed by ecdysone 20-monooxygenase assessments using a radioenzymological assay. Four of the five anthraquinones exhibited $I_{50}$ 's of about $4 \times 10^{-6}$ to $6 \times 10^{-2} \mathrm{M}$. The most effective inhibitors were 2-methoxy-1,4-anthraquinone and 1,4-anthraquinone followed by 9 -hydroxy-1,4 anthraquinone and 9-methoxy-1,4-anthraquinone. At lower concentrations the latter anthraquinone stimulated E20M activity. Quinizarin was less inhibitory and 2-hydroxy-1,4-anthraquinone was essentially without effect. Significantly, these studies make evident for the first time that anthraquinones can affect insect E20M activity, and thus insect endocrine regulation and development, and that a relationship between anthraquinone structure and effectiveness is apparent. These studies represent the first demonstrations of anthraquinones affecting any steroid hydroxylase system.
\end{abstract}

"This paper is dedicated with admiration to the legacy of Dr. Stan L. Smith, without whom this work and studies like it would not have been initiated."

\section{Introduction}

Ecdysone 20-monooxygenase (E.C. 1.14.99.22, E20M) is the insect cytochrome P450-dependent steroid hydroxylase responsible for the conversion of the arthropod molting hormone ecdysone (E) to its more active metabolite, namely, 20 -hydroxyecdysone $(20 \mathrm{E})[1,2]$. The nature, regulation, and molecular biology of E20M were elucidated predominantly employing the tobacco hornworm, Manduca sexta, as the model [3-8]. Indeed, the developmental impact of E20M was made evident in midgut tissue of the $M$. sexta fifth larval instar where E20M activity increases 50 -fold between days four and five of the stadium and this increase is inextricably tied to the onset of wandering stage behavior $[1,8,9]$. Moreover, the timing conferred by pulses of $20 \mathrm{E}$ was found to be critical to all stages of insect development $[1,10]$. 
The E20M system, therefore, represents a crucial target in terms of potential remediation and regulation of pestilent insects.

A number of plant allelochemicals, considered to have evolved to aid plants in their resistance to insect phytophagy, can affect insect steroid hydroxylase function [1114]. Amongst these allelochemicals are limonoids, labdane diterpenoids, and polyketides that include flavonoids and some naphthoquinones [12-17].

Anthraquinones are compounds that are noted in plants, fungi, lichens, and insects and these compounds, or derivatives, are commonly used commercially in dyestuffs and for antineoplastic drug preparations [18-20]. The anthraquinone, quinizarin, is the usual starting material for the syntheses of other anthraquinones given its availability, affordability, and adaptability to a variety of chemical procedures, in addition to the fact that these products are readily purified chromatographically [19-21]. Based on the relationship of quinizarin to other plant allelochemicals and, more importantly, the fact that it lends itself readily to chemical manipulations allowing for substituted anthraquinone syntheses, the potential for quinizarin and synthetic derivatives to serve as endocrine/developmental effectors in insects by affecting the E20M system was apparent. Aside from the fact that the syntheses of anthraquinones permitted, for the first time, a study of chemical structure/function relationships as related to changes in E20M activity, they also permitted a first evaluation of the effects of these compounds on any steroid hydroxylase. Accordingly, an evaluation was pursued of the degrees to which quinizarin and five anthraquinone derivatives synthesized from quinizarin affect E20M activity in midgut tissues of the insect model, M. sexta.

\section{Materials and Methods}

2.1. Animal Maintenance. Animals used in these studies were day five, gate II, nondiapausing fifth instar larvae of the tobacco hornworm, M. sexta. They were reared and staged as described previously [22].

2.2. Tissue Preparation and Homogenization. Midgut tissues from day five, gate II, fifth instar larvae of $M$. sexta were dissected and rinsed in Lepidopteran Ringer's solution at $4^{\circ} \mathrm{C}$ [14]. Following dissection, tissues were blotted to surface dryness on bibulous paper, weighed, and homogenized, at $20 \mathrm{mg}$ tissue/mL, in $50 \mathrm{mM}$ sodium phosphate buffer $(\mathrm{pH}$ 7.5 ) containing $250 \mathrm{mM}$ sucrose, using a tissue grinder with a motor driven Teflon pestle $(275 \mathrm{rpm}, 10$ strokes $)$ at $0^{\circ} \mathrm{C}$.

2.3. E20M Assay. E20M activity was quantified using an in vitro radioenzymological assay [3, 9]. For these assessments, $0.05 \mathrm{~mL}$ aliquots of insect midgut homogenate (containing $1 \mathrm{mg}$ tissue equivalent) were added to $0.05 \mathrm{~mL}$ of homogenization buffer, without sucrose, containing $3.3 \times 10^{-7} \mathrm{M}$ $\left[23,24-{ }^{3} \mathrm{H}_{2}\right]-\mathrm{E} ; 1.6 \times 10^{-3} \mathrm{M} \mathrm{NADPH}$; and one of the six anthraquinones evaluated in concentrations from $1 \times 10^{-8}$ to 1 $\times 10^{-3} \mathrm{M}$ in the assay (assuming full anthraquinone solubility in the assay medium and no selective partitioning into the membrane environment).

Anthraquinones were suspended in $100 \%$ ethanol so that the concentrations in the assays were as listed. Ethanol was evaporated prior to assessments as detailed for ecdysteroid additions to the assay [3]. Contents were mixed by vortexing the assay tubes and incubated at $35^{\circ} \mathrm{C}$ for $30 \mathrm{~min}$ with constant agitation. All assays were run in duplicate with zerotime controls and the incubations were terminated with the addition of $1.5 \mathrm{~mL}$ of $100 \%$ ethanol. Following termination, the assay tubes were centrifuged at $8,000 \times \mathrm{g}$ for $10 \mathrm{~min}$ to collect precipitated protein. Subsequently, $0.15 \mathrm{~mL}$ aliquots of the assay supernatant (containing $10,000 \mathrm{dpm}$ ) plus $10 \mu \mathrm{L}$ of ethanol containing $200 \mu \mathrm{g}$ of non-radiolabeled E and $20 \mathrm{E}$ standards were evaporated to dryness.

The residues were dissolved in methanol and streaked onto analytical thin layer chromatography plates $(0.25 \mathrm{~mm}$ silica gel 60, F-254, E. Merck, Darmstadt, Germany). The plates were developed in a solvent system of chloroform and 95\% ethanol $(4: 1, \mathrm{v} / \mathrm{v})$. After chromatogram development the $\mathrm{E}$ and $20 \mathrm{E}$ bands were visualized under short wavelength UV light. The visualized ecdysteroid bands were scraped into individual scintillation vials, suspended in $10 \mathrm{~mL}$ of scintillation fluid, and counted using a Beckman model 3800 scintillation counter $\left({ }^{3} \mathrm{H}\right.$ counting efficiency, 60\%).

Control E20M activity was expressed as pg $20 \mathrm{E}$ formed $/ \mathrm{min} / \mathrm{mg}$ tissue equivalent. The effects of anthraquinones on E20M activity were expressed as a percent of controls $( \pm$ SEM). Prior studies, using both normal and reverse phase chromatography, confirmed $20 \mathrm{E}$ as the product of this in vitro assay [3, 23-25].

2.4. Spectrophotometric Assessments of Potential Background Oxidation or Reduction of $\operatorname{NADP}(H)$ by the Anthraquinones. Potential oxidation of NADPH was evaluated spectrophotometrically employing a $1 \mathrm{~mL}$ reading volume containing $0.50 \mathrm{~mL}$ of $5 \mathrm{mM}$ sodium phosphate $(\mathrm{pH} 7.5)$ and $1.6 \times 10^{-4} \mathrm{M}$ NADPH. To this was added $0.48 \mathrm{~mL}$ buffer without NADPH followed by $0.02 \mathrm{~mL}$ of the six individual anthraquinones in $100 \%$ ethanol to contain the concentrations, that is, $1 \times$ $10^{-8}$ to $1 \times 10^{-3} \mathrm{M}$, evaluated. Absorbance at $340 \mathrm{~nm}$ was measured over a $10 \mathrm{~min}$ period employing a Shimadzu UV1700 spectrophotometer.

To assess potential background reduction of $\mathrm{NADP}^{+}$, acetylpyridine $\mathrm{NADP}^{+}\left(\mathrm{AcPyADP}^{+}\right)$was used as the acceptor. The $1 \mathrm{~mL}$ reading volume contained $0.50 \mathrm{~mL}$ buffer containing $5 \mathrm{mM}$ sodium phosphate $(\mathrm{pH} 7.5)$ and $1.6 \times$ $10^{-4} \mathrm{M} \mathrm{AcPyADP}^{+}$. To this was added $0.48 \mathrm{~mL}$ buffer without $\mathrm{AcPyADP}^{+}$followed by $0.02 \mathrm{~mL}$ of the six individual anthraquinones in $100 \%$ ethanol to contain the concentrations, that is, $1 \times 10^{-3}$ to $1 \times 10^{-8} \mathrm{M}$, evaluated. Absorbance at $375 \mathrm{~nm}$ was measured over $10 \mathrm{~min}$ employing a Shimadzu UV-1700 spectrophotometer.

2.5. Anthraquinone Synthesis. 1,4-Anthraquinone was prepared by quinizarin reduction according to established methods [20]. 
<smiles>O=C1c2ccccc2C(=O)c2c(O)ccc(O)c21</smiles>

Quinizarin (QZ)

(a)<smiles>O=C1C=CC(=O)c2cc3ccccc3cc21</smiles>

1,4-Anthraquinone (AQ)

(c)

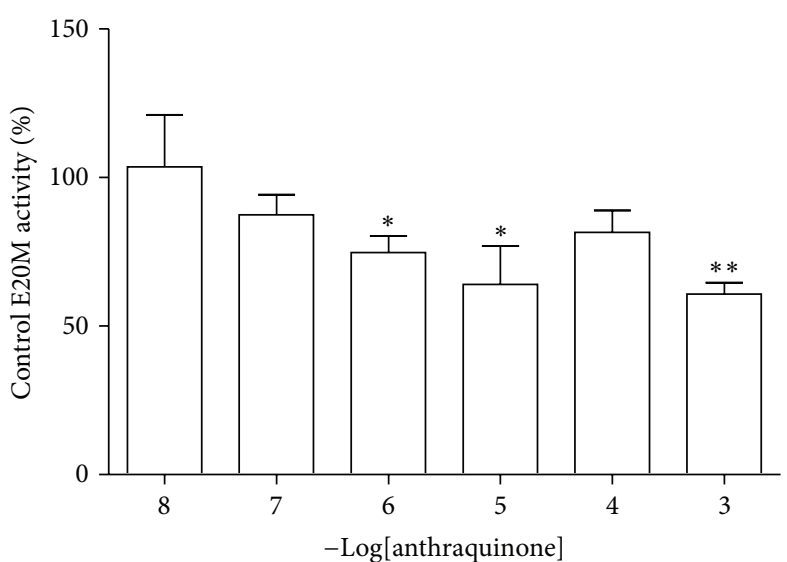

(b)

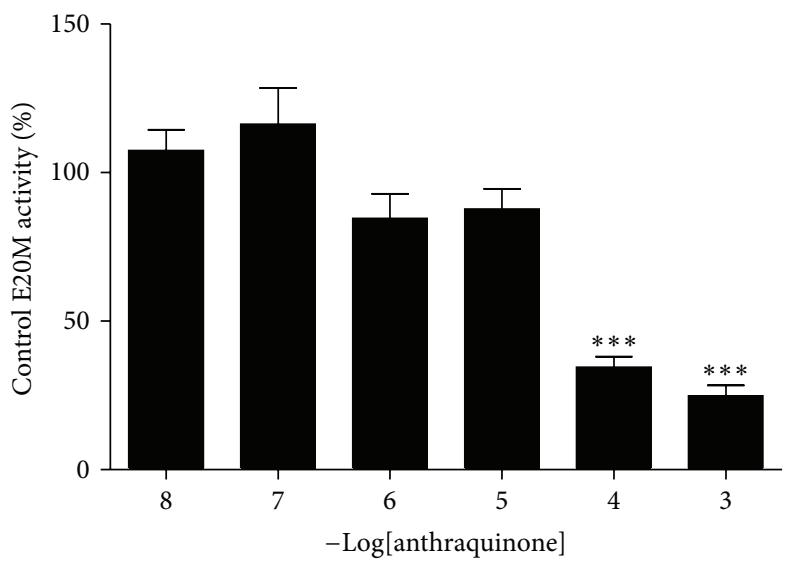

(d)

FIGURE 1: (a) and (c), the structures of quinizarin (QZ) and 1,4-anthraquinone (AQ); (b) and (d), the effects QZ and AQ, expressed as percent of controls, on E20M activity of day 5 midgut homogenates of gate II fifth instar Manduca sexta. Each value including controls is the mean \pm SEM of three determinations done in duplicate. Control E20M activity for QZ was $403 \pm 2.3 \mathrm{pg} 20 \mathrm{E}$ formed $/ \mathrm{min} / \mathrm{mg}$ tissue, while control E20M activity for AQ was $485 \pm 4.9 \mathrm{pg} 20 \mathrm{E}$ formed $/ \mathrm{min} / \mathrm{mg}$ tissue. Asterisks indicate significant differences compared to controls: ${ }^{*} P<0.05$; ${ }^{* *} P<0.01 ;{ }^{* * *} P<0.001$.

Purification by flash chromatography using chloroform as the eluent afforded pure 1,4-anthraquinone $(2.8 \mathrm{~g}, 81 \%)$. The identity and purity of this compound were confirmed by melting point determination, UV-Vis spectroscopy, infrared spectroscopy, ${ }^{1} \mathrm{H}$-NMR, ${ }^{13} \mathrm{C}-\mathrm{NMR}$, and mass spectroscopy.

The 9-hydroxy and 9-methoxy derivatives of quinizarin were prepared as previously described [26]. The 2-hydroxy and 2-methoxy derivatives were prepared by known methods [27-29].

2.6. Statistical Analyses. All statistical differences between E20M activities of anthraquinone treated and control preparations were determined using ANOVA analysis followed by Tukey's Post Hoc comparison of the means of the group. Differences with a $P$ value $\leq 0.05$ were considered significant (JMP11, SAS).

2.7. Materials. Radiolabeled $\left[23,24-{ }^{3} \mathrm{H}_{2}\right]-\mathrm{E}$ (stock of $55 \mathrm{ci} / \mathrm{mmol}$, radiopurity > 99\%) used in the $\mathrm{E} 20 \mathrm{M}$ assays was purchased from New England Nuclear, Boston, MA. The standards for the assay, that is, E and $20 \mathrm{E}$, were purchased from Fluka Chemical, Ronkonkoma, NY. $\mathrm{NADPH}, \mathrm{AcPyADP}^{+}$, and quinizarin (96\% pure) were from Sigma-Aldrich, St. Louis, MO. Quinizarin was purified further (99\%) by flash chromatography on silica gel using chloroform as the solvent. Salts and organic solvents were purchased from Fisher Scientific, Cleveland, $\mathrm{OH}$. Scintillation fluid (Ultima Gold) was obtained from PerkinElmer, Waltham, MA.

\section{Results}

The abbreviations used for the anthraquinones evaluated are as follows: the parent compound quinizarin, QZ; 1,4-anthraquinone, AQ; 2-hydroxy-1,4-anthraquinone, 2OH; 2-methoxy-1,4-anthraquinone, $2 \mathrm{MeO}$; 9-hydroxy-1,4anthraquinone, 9OH; 9-methoxy-1,4-anthraquinone, 9MeO. 
<smiles>O=C1C=C(O)C(=O)c2cc3ccccc3cc21</smiles>

2-Hydroxy-1,4-anthraquinone $(2 \mathrm{OH})$

(a)

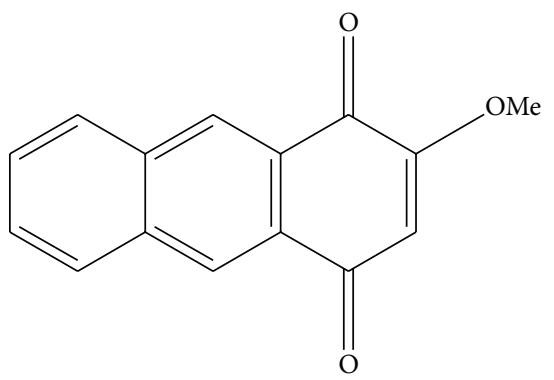

2-Methoxy-1,4-anthraquinone (2MeO)

(c)

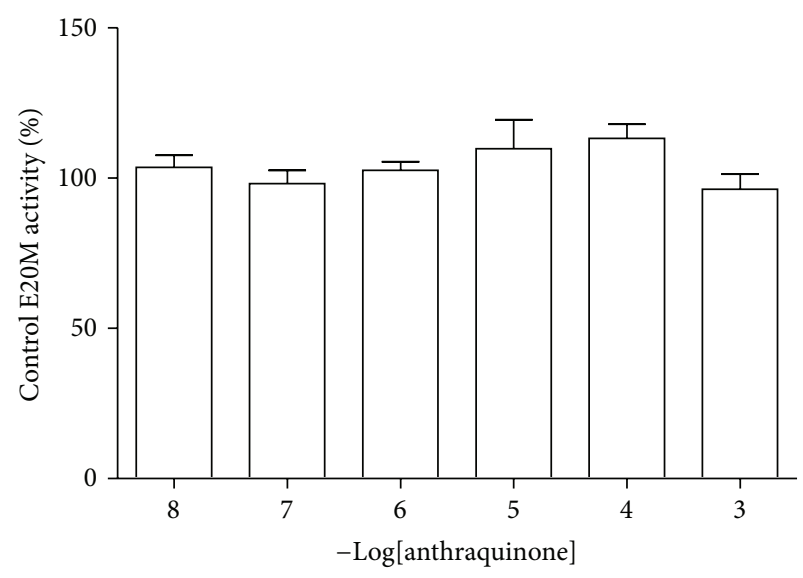

(b)

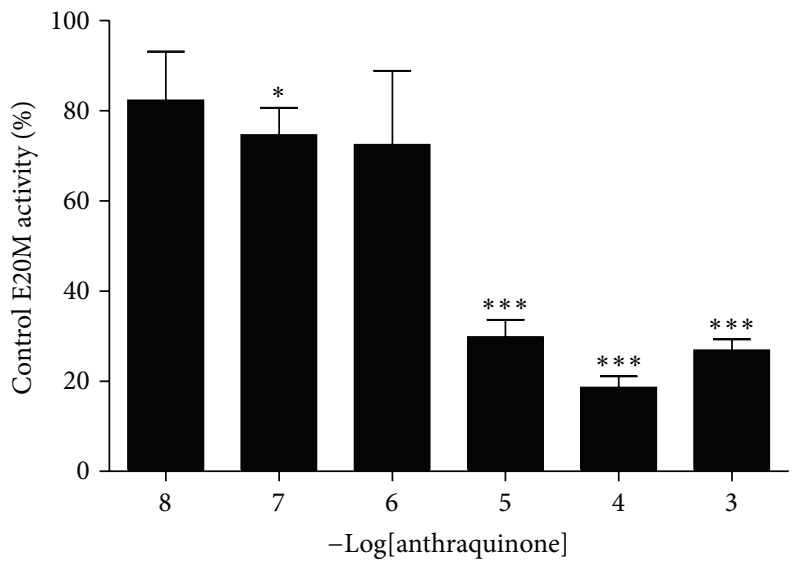

(d)

FIGURE 2: (a) and (c), the structures of 2-hydroxy-1,4-anthraquinone (2OH) and 2-methoxy-1,4-anthraquinone (2MeO); (b) and (d), the effects of $2 \mathrm{OH}$ and $2 \mathrm{MeO}$, expressed as percent of controls, on E20M activity of day 5 midgut homogenates of gate II fifth instar Manduca sexta. Each value including controls is the mean \pm SEM of three determinations done in duplicate. Control E20M activity for $2 \mathrm{OH}$ was $516 \pm 4.5 \mathrm{pg} 20 \mathrm{E}$ formed $/ \mathrm{min} / \mathrm{mg}$ tissue, while control E20M activity for $2 \mathrm{MeO}$ was $644 \pm 5.4 \mathrm{pg}$ of $20 \mathrm{E}$ formed $/ \mathrm{min} / \mathrm{mg}$ tissue. Asterisks indicate significant differences compared to controls: ${ }^{*} P<0.05 ;{ }^{* * *} P<0.001$.

In the absence of enzyme, none of the anthraquinones evaluated acted to either reduce $\mathrm{NADP}^{+}$or oxidize $\mathrm{NADPH}$ nor did these compounds elicit conversion of $\mathrm{E}$ to $20 \mathrm{E}$.

The parent compound, QZ (Figure 1(a)), significantly inhibited $M$. sexta midgut E20M activity in the concentration range of $10^{-6}$ to $10^{-3} \mathrm{M}$. Although at $10^{-4} \mathrm{M}$ inhibition was suggested, it was not statistically significant (Figure 1(b)). Whereas the degrees of inhibition at these concentrations significantly differed from controls, with the greatest inhibition being $61 \%$ of controls at $10^{-3} \mathrm{M}$, and a decrease in inhibition was suggested with decreasing QZ content, the degrees of inhibition in the $10^{-6}$ to $10^{-3} \mathrm{M}$ range did not differ significantly from one another. At the lower concentrations of QZ, that is, $10^{-8}$ and $10^{-7} \mathrm{M}$, the changes in E20M activity were not statistically significantly different from controls (Figure 1(b)).

With the chemical placement of the quinone moiety at a terminal position, accompanied by the removal of hydroxyl groups, that is, synthesis of AQ (Figure 1(c)), significant inhibition of midgut E20M activity was noted. At concentrations of $10^{-4}$ and $10^{-3} \mathrm{M}, \mathrm{E} 20 \mathrm{M}$ activity was significantly diminished to $34 \%$ and $25 \%$, respectively, as compared to controls (Figure 1(d)). Whereas degrees of stimulation at $10^{-8}$ and $10^{-7} \mathrm{M}$ followed by inhibition at $10^{-6}$ and $10^{-5} \mathrm{M}$ were suggested with $\mathrm{AQ}$, these latter differences in E20M activity did not differ statistically from controls. At $10^{-4}$ and $10^{-3} \mathrm{M}$, the inhibitions of enzyme activity significantly differed from controls as well as the activities noted at $10^{-8}$ and $10^{-7} \mathrm{M}$. AQ treatment at $10^{-3} \mathrm{M}$ was significantly more inhibitory than at $10^{-5} \mathrm{M}$ and both treatments significantly differed from treatment with $10^{-8} \mathrm{M}$ AQ (Figure $1(\mathrm{~d})$ ).

Upon chemical addition of an adjacent hydroxyl function to the terminal quinone of $A Q$, resulting in the synthesis of $2 \mathrm{OH}$ (Figure $2(\mathrm{a})$ ), the anthraquinone was essentially ineffective in altering E20M activity. Although a degree of stimulation at $10^{-4} \mathrm{M}$ and inhibition at $10^{-3} \mathrm{M}$, respectively, 
<smiles>O=C1C=CC(=O)c2c1cc1ccccc1c2O</smiles>

9-Hydroxy-1,4-anthraquinone $(9 \mathrm{OH})$

(a)

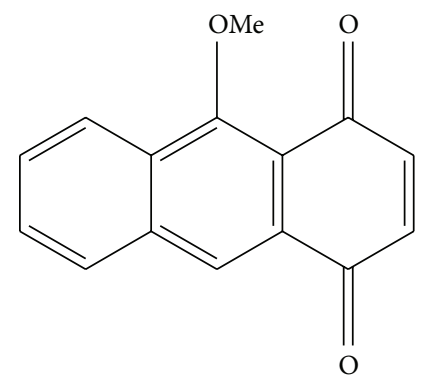

9-Methoxy-1,4-anthraquinone (9MeO)

(c)

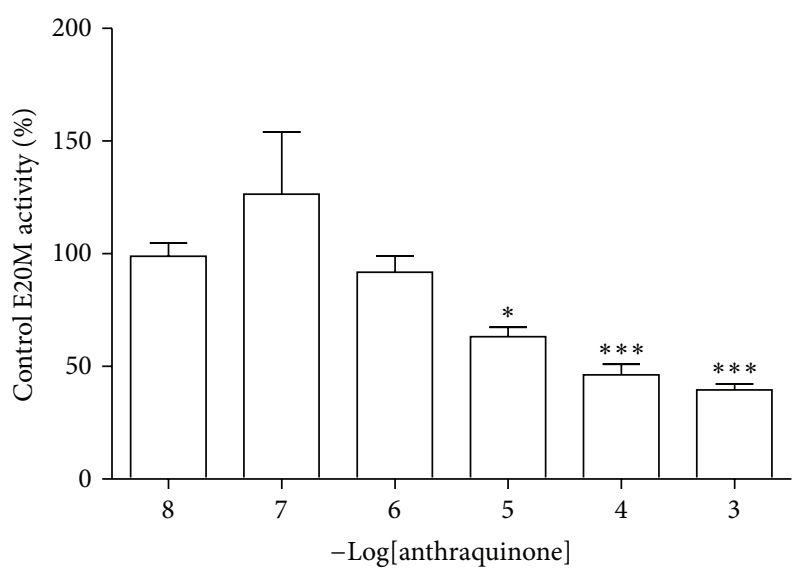

(b)

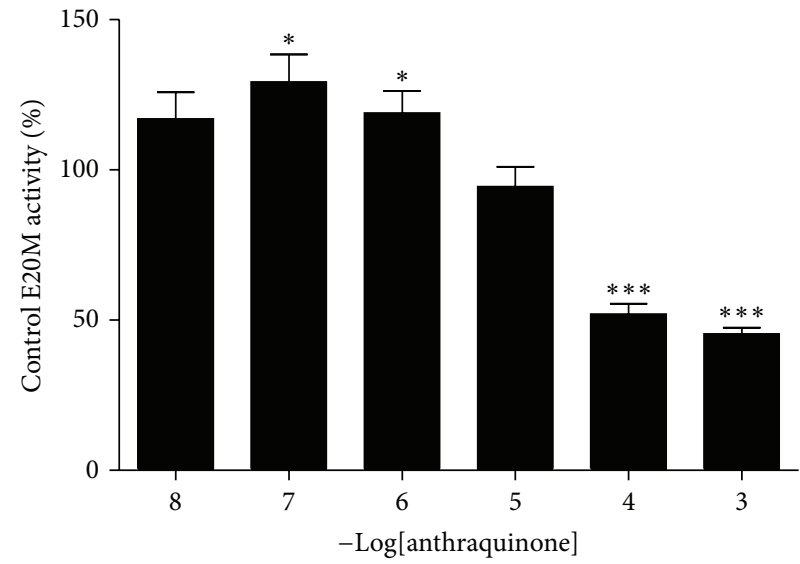

(d)

FIGURE 3: (a) and (c), the structures of 9-hydroxy-1,4-anthraquinone (9OH) and 9-methoxy-1,4-anthraquinone (9MeO); (b) and (d) the effects of $9 \mathrm{OH}$ and $9 \mathrm{MeO}$, expressed as per cent of controls, on E20M activity of day 5 midgut homogenates of gate II fifth instar Manduca sexta. Each value including controls is the mean \pm SEM of three determinations done in duplicate. Control E20M activity for $90 \mathrm{OH}$ was $377 \pm 1.9 \mathrm{pg} 20 \mathrm{E}$ formed/min/mg tissue, while control E20M activity for $9 \mathrm{MeO}$ was $237 \pm 1.4 \mathrm{pg}$ of $20 \mathrm{E}$ formed $/ \mathrm{min} / \mathrm{mg}$ tissue. Asterisks indicate significant differences compared to controls: ${ }^{*} P<0.05 ;{ }^{* * *} P<0.001$.

were suggested, no significant differences were noted between experimental and control assessments throughout the concentration range of $2 \mathrm{OH}$ evaluated (Figure 2(b)).

Addition of a methoxy group, in lieu of a hydroxyl group, to the terminal quinone of $\mathrm{AQ}$ resulted in an inhibitory anthraquinone, namely, $2 \mathrm{MeO}$ (Figure 2(c)). At the three highest concentrations examined, that is, $10^{-5}$ to $10^{-3} \mathrm{M}$, midgut E20M activities were decreased significantly, 30\%, $19 \%$, and $27 \%$, respectively, as compared to controls. At the concentration range of $10^{-8}$ to $10^{-6} \mathrm{M}$, lesser degrees of inhibition were suggested, although the $10^{-7} \mathrm{M}$ treatment proved significant at $73 \%$ of control activity (Figure $2(\mathrm{~d})$ ).

With the placement of a hydroxyl function at carbon 9 of $\mathrm{AQ}$, that is, the synthesis of $9 \mathrm{OH}$ (Figure 3(a)), a molecule capable of inhibiting E20M activity was synthesized (Figure 3(b)). At $10^{-5}$ to $10^{-3} \mathrm{M}, 9 \mathrm{OH}$ exerted significant inhibitions, namely, $63 \%$ to $40 \%$ of controls. At the lower concentrations of $9 \mathrm{OH}$ examined, that is, $10^{-8}$ to $10^{-6} \mathrm{M}$, no significant changes in E20M were noted, although a suggested increase in activity at $10^{-7} \mathrm{M} 9 \mathrm{OH}$ was apparent. However, the levels of E20M activity observed at $10^{-5}$ and $10^{-4} \mathrm{M}$ $9 \mathrm{OH}$ were significantly lower than that observed for $10^{-7} \mathrm{M}$ (Figure 3(b)).

With chemical substitution of a methoxy function for the 9 hydroxyl group of $9 \mathrm{OH}$, that is, the synthesis of $9 \mathrm{MeO}$ (Figure 3(c)), a molecule that displayed concentration dependent stimulatory and inhibitory effects on E20M was made (Figure 3(d)). In the concentration range of $10^{-8}$ to $10^{-6} \mathrm{M}$, stimulation was apparent with statistically significant increases noted at $10^{-7}$ and $10^{-6} \mathrm{M}$, that is, $136 \%$ and $130 \%$ of controls, respectively. Conversely, in the concentration range from $10^{-5}$ to $10^{-3} \mathrm{M}, 9 \mathrm{MeO}$ inhibition was apparent with statistically significant effects noted at $10^{-4}$ and $10^{-3} \mathrm{M}$, that is, $59 \%$ and $46 \%$, respectively (Figure 3(d)).

The efficacy of QZ and the synthesized anthraquinones in terms of E20M inhibition is reflected in the $I_{50}$ values listed in Table 1. The most effective diminution of E20M 
TABLE 1: $I_{50}$ Values for the anthraquinones tested.

\begin{tabular}{lc}
\hline Anthraquinone & $I_{50}$ value \\
\hline 2-Methoxy-1,4-anthraquinone & $4 \times 10^{-5} \mathrm{M}$ \\
1,4-Anthraquinone & $3 \times 10^{-4} \mathrm{M}$ \\
9-Hydroxy-1,4-anthraquinone & $1 \times 10^{-3} \mathrm{M}$ \\
9-Methoxy-1,4-anthraquinone & $2 \times 10^{-3} \mathrm{M}$ \\
Quinizarin & $6 \times 10^{-2} \mathrm{M}$ \\
2-Hydroxy-1,4-anthraquinone & $2 \times 10^{4} \mathrm{M}$ \\
\hline
\end{tabular}

activity was noted with $2 \mathrm{MeO}$. The $I_{50}$ for AQ was essentially an order of magnitude greater and both $9 \mathrm{OH}$ and $9 \mathrm{MeO}$, respectively, displayed values reflecting a lesser potency than AQ. The parent compound, QZ, was less effective than the above mentioned derivatives. In turn, the anthraquinone least capable of exerting an effect on $M$. sexta E20M was $2 \mathrm{OH}$ (Table 1).

\section{Discussion}

The effects of plant allelochemicals on insect E20M activity have been noted not only with respect to the model, $M$. sexta, but with other insect systems as well, for example, Aedes aegypti (mosquito), Drosophila melanogaster (fruit fly), and Spodoptera frugiperda (fall army worm) [12-17, 30, 31]. However, until the present study, no data relating to the effects of anthraquinone allelochemicals on insect E20M were available. This is of particular significance inasmuch as the anthraquinone allelochemical, QZ, readily lends itself to chemical derivatization, thereby allowing for studies of the relationship of chemical structure to the effects of the resulting synthetic compounds. The data presented in our study constitute the first demonstrations of anthraquinones effectively inhibiting (and to a lesser degree stimulating) $M$. sexta E20M activity in a dose-dependent fashion. Moreover, the present study represents the first demonstration that anthraquinones affect a P-450 dependent steroid hydroxylase in any invertebrate or vertebrate system.

Considered within the context of chemical reactivity, some characteristics of the examined anthraquinones could impact potential interactions with the M. sexta E20M system [32]. For example, terminal placement of the quinone moiety and removal of the hydroxyl groups from QZ allow for an increased potential for nucleophilic activity on the part of the resulting AQ. Furthermore, the placement of a hydroxyl moiety at the number 2 carbon of AQ allows for a tautomeric shift and orthoquinone formation of the resulting $2 \mathrm{OH}$ compound. In turn, such tautomerization could reduce potential interactions with the E20M system. Placement of a hydroxyl group at the number 9 carbon position of AQ potentiates hydrogen bonding between hydroxyl and carbonyl functions of $9 \mathrm{OH}$ while addition of a methoxy group to the number 2 carbon of AQ allows the electron-donating ability of the methoxy group to render the adjacent position of the $2 \mathrm{MeO}$ quinone more susceptible to cationic interaction.

The present study made evident that the effects of the anthraquinones examined on $M$. sexta E20M activity were not attributable to any nonenzymatic reactions affecting either the $\operatorname{NADP}(\mathrm{H})$ content in the assays or the conversion of E to E20. Clearly, with the exception of $2 \mathrm{OH}$, syntheses performed using the QZ parent resulted in compounds displaying enhanced inhibition of $M$. sexta day five, fifth larval stage E20M activity. In terms of comparative inhibitory efficacy, the most active synthetic product was $2 \mathrm{MeO}$ followed by $\mathrm{AQ}$, the latter being about an order of magnitude less inhibitory. Although treatment of $M$. sexta enzyme preparations with $2 \mathrm{OH}$ proved essentially ineffective and QZ was the least effective of the compounds displaying significant inhibition, it is noteworthy that both the $9 \mathrm{OH}$ and $9 \mathrm{MeO}$ derivatives were about an order of magnitude more inhibitory than QZ as reflected in $I_{50}$ values.

The impact of the chemical characteristics of the anthraquinones and the mechanism(s) of anthraquinone inhibition of M. sexta E20M certainly merit further study; our data make apparent marked differences in inhibition that are dependent upon the positional alkyl and hydroxyl substitutions of QZ-derived AQ. An additional underpinning for further studies is noted in our findings that lower concentrations of $9 \mathrm{MeO}$ significantly stimulated E20M activity while higher concentrations were significantly inhibitory. Prior evaluations of plant allelochemicals on insect E20M activity demonstrated both inhibitory and stimulatory effects [12-17]. Yu [30, 31] noted allelochemical stimulation of the juvenile hormone III oxidase (a monooxygenase) as well as E20M of the fall army worm, S. frugiperda. Indeed, more recently, several plant flavonoids were found to be inhibitory/stimulatory with respect to other insect enzymes, namely, the mitochondrial, membrane associated NADPH $\rightarrow \mathrm{NAD}^{+}$transhydrogenase, $\mathrm{NADH}$ oxidase, and succinate dehydrogenase systems of $M$. sexta fifth larval instar midgut and fat body [33]. Thus, additional potential targets for the study of anthraquinone effects also merit consideration.

In light of their effects on E20M, and therefore insect endocrine regulated development and potential insect control, further studies of the anthraquinones evaluated as well as other anthraquinone derivatives are warranted. In addition, the relationship between anthraquinone molecular structure and effects on E20M was made apparent for the first time. As the data presented are the first indications of anthraquinones affecting a steroid hydroxylase system, comparative evaluations of the impact of anthraquinones on steroid hydroxylases generally also will be most informative.

\section{Conclusions}

This study shows for the first time that QZ and anthraquinones synthesized from the QZ parent compound warrant evaluation as effectors of a crucial enzyme mediating arthropod molting and metamorphosis. This study revealed that strategic placement of functional groups on the anthraquinone nucleus has significant effects on the inhibitory/stimulatory activity of these compounds. In light of their effects on insect development, via affecting E20M activity, and potential effects on steroid hydroxylases in general, further studies are clearly warranted. 


\section{Conflict of Interests}

The authors declare that there is no conflict of interests regarding the publication of this paper.

\section{Acknowledgments}

Support of the Department of Biological Sciences, Bowling Green State University, and Grant SAF2009-10399 awarded by MICINN from the Spanish Government to Maria Teresa Molina are graciously noted. Sandra Taliansky thanks MICINN for a graduate scholarship. Gratitude is expressed to Drs. David Morgan and Martin Mitchell for their interest in the early stages of this work.

\section{References}

[1] S. L. Smith, "Regulation of ecdysteroid titer: synthesis," in Comprehensive Insect Physiology, Biochemistry and Pharmacology, G. A. Kerkut and L. I. Gilbert, Eds., pp. 295-341, Pergamon Press, Oxford, UK, 1985.

[2] R. Lafont, C. DauphinVillemant, J. T. Warren, and H. Rees, "3.3-ecdysteroid chemistry and biochemistry," in Comprehensive Molecular Insect Science, I. G. Lawrence, I. Kostas, and S. G. Sarjeet, Eds., pp. 125-195, Elsevier, Amsterdam, The Netherlands, 2005.

[3] S. Lee Smith, W. E. Bollenbacher, D. Y. Cooper, H. Schleyer, J. J. Wielgus, and L. I. Gilbert, "Ecdysone 20-monooxygenase: Characterization of an insect cytochrome P-450 dependent steroid hydroxylase," Molecular and Cellular Endocrinology, vol. 15, no. 3, pp. 111-133, 1979.

[4] L. I. Gilbert, W. E. Bollenbacher, W. Goodman et al., "Hormones controlling insect metamorphosis.," Recent Progress in Hormone Research, vol. 36, pp. 401-449, 1980.

[5] R. Feyereisen, "4.1-Insect cytochrome P450," in Comprehensive Molecular Insect Science, I. G. Lawrence, I. Kostas, and S. G. Sarjeet, Eds., pp. 1-77, Elsevier, Amsterdam, The Netherlands, 2005.

[6] K. F. Rewitz, R. Rybczynski, J. T. Warren, and L. I. Gilbert, "Developmental expression of Manduca shade, the P450 mediating the final step in molting hormone synthesis," Molecular and Cellular Endocrinology, vol. 247, no. 1-2, pp. 166-174, 2006.

[7] L. I. Gilbert, R. Rybczynski, and J. T. Warren, "Control and biochemical nature of the ecdysteroidogenic pathway," Annual Review of Entomology, vol. 47, pp. 883-916, 2002.

[8] L. I. Gilbert and K. F. Rewitz, "The function and evolution of the halloween genes: the pathway to the arthropod molting hormone," in Ecdysone: Structures and Functions, G. Smagghe, Ed., pp. 231-269, Springer, Amsterdam, The Netherlands, 2009.

[9] M. J. Mitchell, J. R. Crooks, D. P. Keogh, and S. L. Smith, "Ecdysone 20-monooxygenase activity during larval-pupaladult development of the tobacco hornworm, Manduca sexta," Archives of Insect Biochemistry and Physiology, vol. 41, no. 1, pp. 24-32, 1999.

[10] C. Drummond and S. Smith, "Ecdysone 20-monooxygenase activity during embryogenesis of the tobacco hornworm, Manduca sexta," Current Topics in Steroid Research, vol. 9, pp. 67-72, 2012.

[11] D. J. Chitwood, M. A. McClure, M. F. Feldlaufer, W. R. Lusby, and T. E. Oliver, "Sterol composition and ecdysteroid content of eggs of the root-knot nematodes Meloidogyne incognita and $M$. arenaria," Journal of Nematology, vol. 19, pp. 352-360, 1987.

[12] M. J. Mitchell, D. P. Keogh, J. R. Crooks, and S. L. Smith, "Effects of plant flavonoids and other allelochemicals on insect cytochrome P-450 dependent steroid hydroxylase activity," Insect Biochemistry and Molecular Biology, vol. 23, no. 1, pp. 6571, 1993.

[13] M. J. Mitchell, S. L. Smith, S. Johnson, and E. D. Morgan, "Effects of the neem tree compounds azadirachtin, salannin, nimbin, and 6-desacetylnimbin on ecdysone 20-monooxygenase activity," Archives of Insect Biochemistry and Physiology, vol. 35, no. 1-2, pp. 199-209, 1997.

[14] M. J. Mitchell, A. I. Brescia, S. L. Smith, and E. D. Morgan, "Effects of the compounds 2-methoxynaphthoquinone, 2-propoxynaphthoquinone, and 2-isopropoxynaphthoquinone on ecdysone 20-monooxygenase activity," Archives of Insect Biochemistry and Physiology, vol. 66, no. 1, pp. 45-52, 2007.

[15] D. P. Keogh, M. J. Mitchell, J. R. Crooks, and S. L. Smith, "Effects of the adenylate cyclase activator forskolin and its inactive derivative 1,9-dideoxyforskolin on insect cytochrome P-450 dependent steroid hydroxylase activity," Experientia, vol. 48, no. 1, pp. 39-41, 1992.

[16] E. D. Morgan, "Azadirachtin, a scientific gold mine," Bioorganic and Medicinal Chemistry, vol. 17, no. 12, pp. 4096-4105, 2009.

[17] M. J. Mitchell and S. L. Smith, "Effects of the chitin synthetase inhibitor plumbagin and its 2-demethyl derivative juglone on insect ecdysone 20-monooxygenase activity," Experientia, vol. 44, no. 11-12, pp. 990-991, 1988.

[18] H.-S. Bien, J. Stawitz, and K. Wunderlich, "Anthraquinone dyes and intermediates," in Ullmann's Encyclopedia of Industrial Chemistry, pp. 1-44, Wiley-VCH Verlag GmbH \& Co. KGaA, 2000.

[19] E. Apostolova, T. Markova, T. Filipova, M. T. Molina, and S. G. Taneva, "Influence of substituted 1,4-anthraquinones on the chlorophyll fluorescence and photochemical activity of pea thylakoid membranes," Journal of Photochemistry and Photobiology B: Biology, vol. 70, no. 2, pp. 75-80, 2003.

[20] M. T. Molina, C. Navarro, A. Moreno, and A. G. Csáky, "Arylation of benzo-fused 1,4-quinones by the addition of boronic acids under dicationic Pd(II)-catalysis," Organic Letters, vol. 11, no. 21, pp. 4938-4941, 2009.

[21] H. H. Reynolds and L. A. Bigelow, "A study of the preparation of quinizarin," Journal of the American Chemical Society, vol. 48, no. 2, pp. 420-422, 1926.

[22] W. G. Goodman, R. O. Carlson, and K. L. Nelson, "Analysis of larval and pupal development in the Tobacco Hornworm (Lepidoptera: Sphingidae), Manduca sexta," Annals of the Entomological Society of America, vol. 78, pp. 70-80, 1985.

[23] S. L. Smith, W. E. Bollenbacher, and L. I. Gilbert, "Ecdysone 20-monooxygenase activity during larval-pupal development of Manduca sexta," Molecular and Cellular Endocrinology, vol. 31, no. 2-3, pp. 227-251, 1983.

[24] S. L. Smith and M. J. Mitchell, "Ecdysone 20-monooxygenase systems in a larval and an adult dipteran. An overview of their biochemistry, physiology and pharmacology," Insect Biochemistry, vol. 16, no. 1, pp. 49-55, 1986.

[25] M. J. Mitchell and S. L. Smith, "Characterization of ecdysone 20-monooxygenase activity in wandering stage larvae of Drosophila melanogaster. Evidence for mitochondrial and microsomal cytochrome P-450 dependent systems," Insect Biochemistry, vol. 16, no. 3, pp. 525-537, 1986. 
[26] P. Jiménez, M. V. Roux, J. Z. Dávalos, and M. T. Molina, “Thermochemistry of 9-hydroxy-1,4-anthraquinone and 9-methoxy1,4-anthraquinone," The Journal of Chemical Thermodynamics, vol. 34, pp. 1117-1126, 2002.

[27] K. Kobayashi, K. Tanaka, T. Uneda, K. Maeda, O. Morikawa, and H. Konishi, "A direct one-pot preparation of naphtho[2,3b]furan-4,9-diones from 2-hydroxy-1,4-naphthoquinones and enamines," Synthesis, no. 9, pp. 1243-1245, 1998.

[28] M. T. Molina, H. Sun, S. Taliansky, A. Carnero, F. Blanco, and M. V. Moneo, "Quinone antitumor compounds, paticularly 1,4anthraquinones and their derivatives, process for their preparation, and their uses," Tech. Rep. 2007026041, The International Patent System, 2007.

[29] E. Barranco, N. Martín, J. L. Segura et al., "Syntheses, electrochemistry and molecular modeling of $\mathrm{N}, \mathrm{N}^{\prime}$ dicyanoquinonediimine (DCNQI) derivatives of substituted 1,4-anthracenediones: precursors for organic metals," Tetrahedron, vol. 49, no. 22, pp. 4881-4892, 1993.

[30] S. J. Yu, "Allelochemical stimulation of ecdysone 20monooxygenase in fall armyworm larvae," Archives of Insect Biochemistry and Physiology, vol. 28, pp. 365-375, 1995.

[31] S. J. Yu, "Allelochemical induction of hormone-metabolizing microsomal monooxygenases in the fall armyworm," Zoological Studies, vol. 39, no. 3, pp. 243-249, 2000.

[32] G. C. H. Derksen, H. A. G. Niederländer, and T. A. van Beek, "Analysis of anthraquinones in Rubia tinctorum L. by liquid chromatography coupled with diode-array UV and mass spectrometric detection," Journal of Chromatography A, vol. 978, no. 1-2, pp. 119-127, 2002.

[33] K. P. Vandock, M. J. Mitchell, and C. F. Fioravanti, "Effects of plant flavonoids on manduca sexta (tobacco hornworm) fifth larval instar midgut and fat body mitochondrial transhydrogenase," Archives of Insect Biochemistry and Physiology, vol. 80, no. 1, pp. 15-25, 2012. 

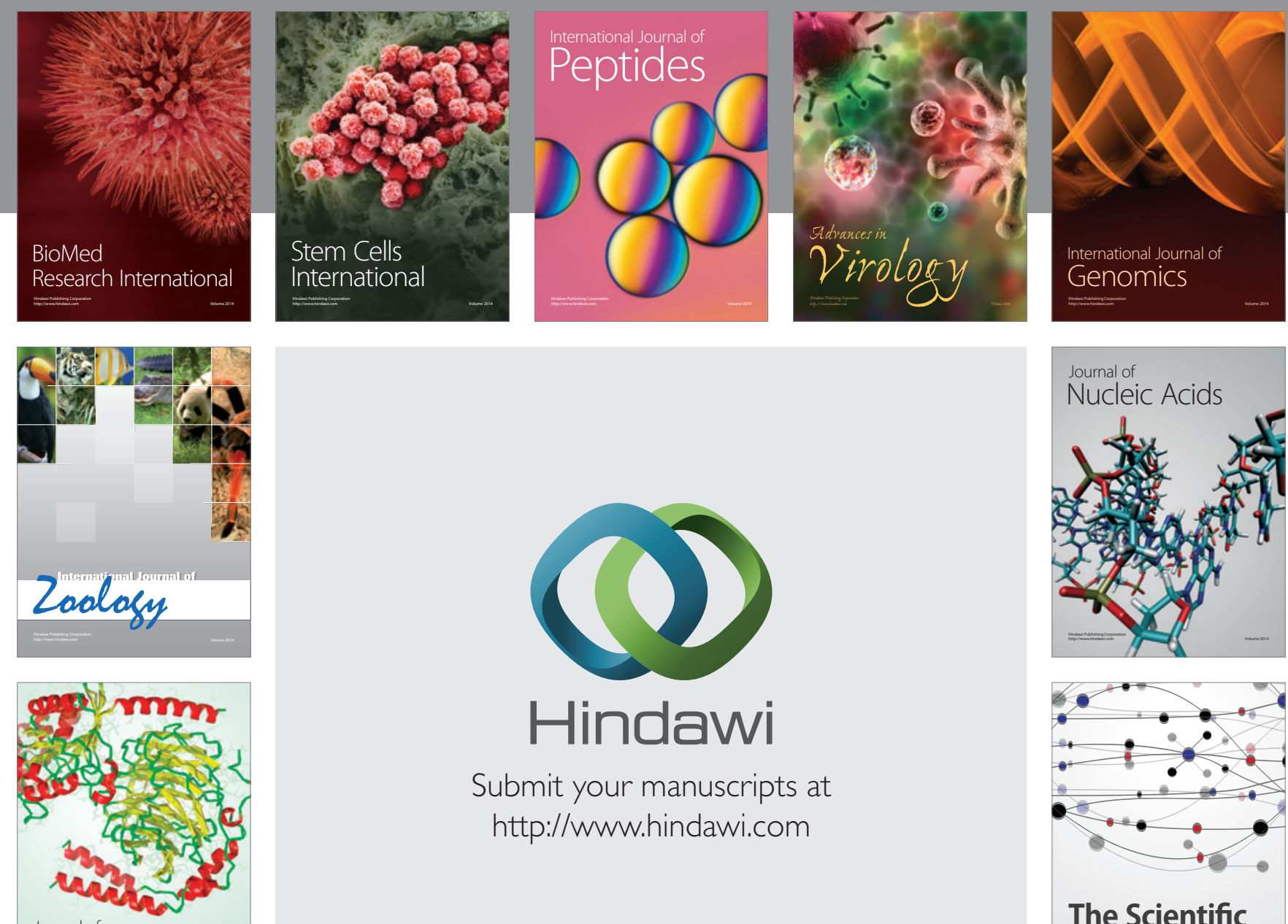

Submit your manuscripts at

http://www.hindawi.com

Journal of
Signal Transduction
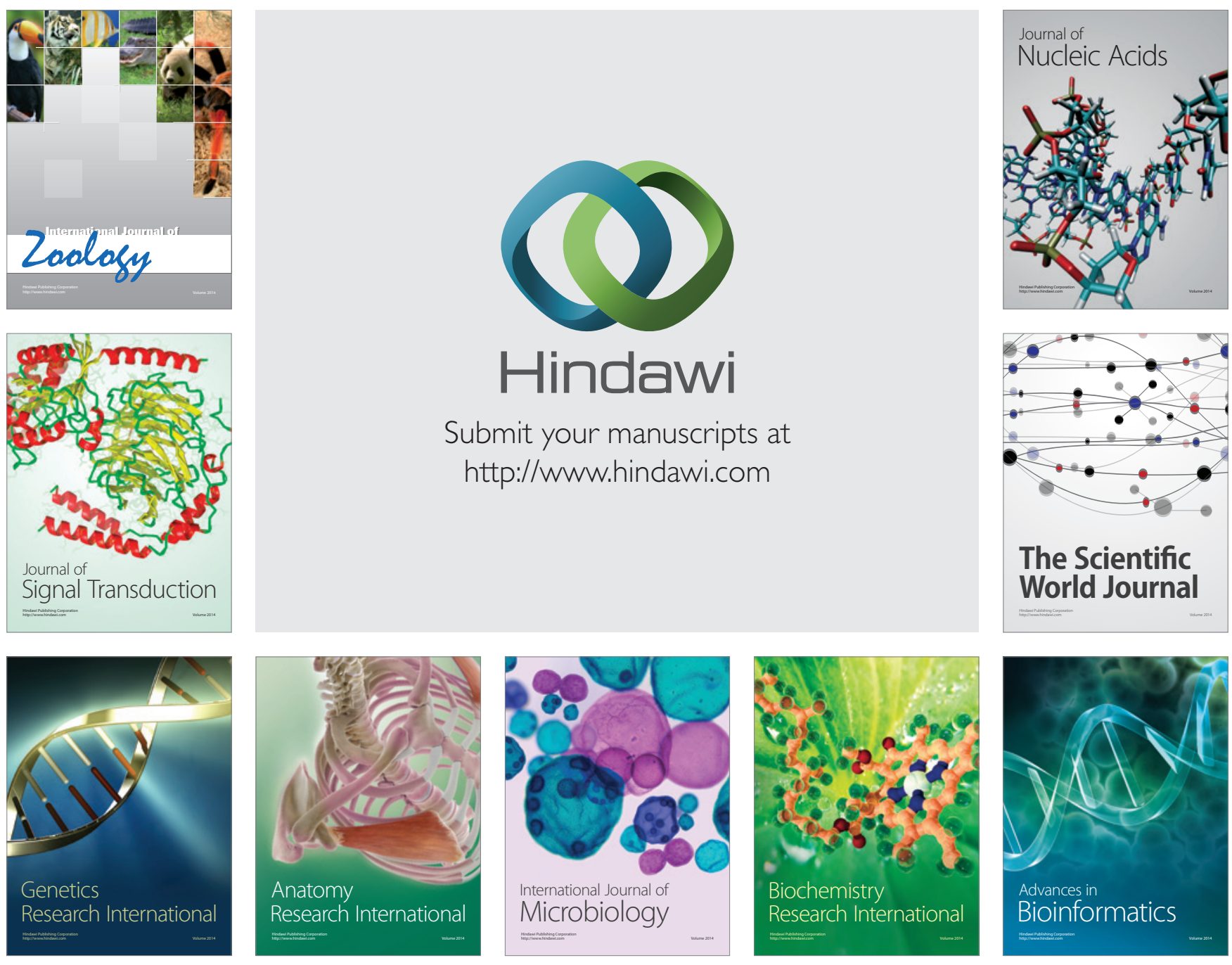

The Scientific World Journal
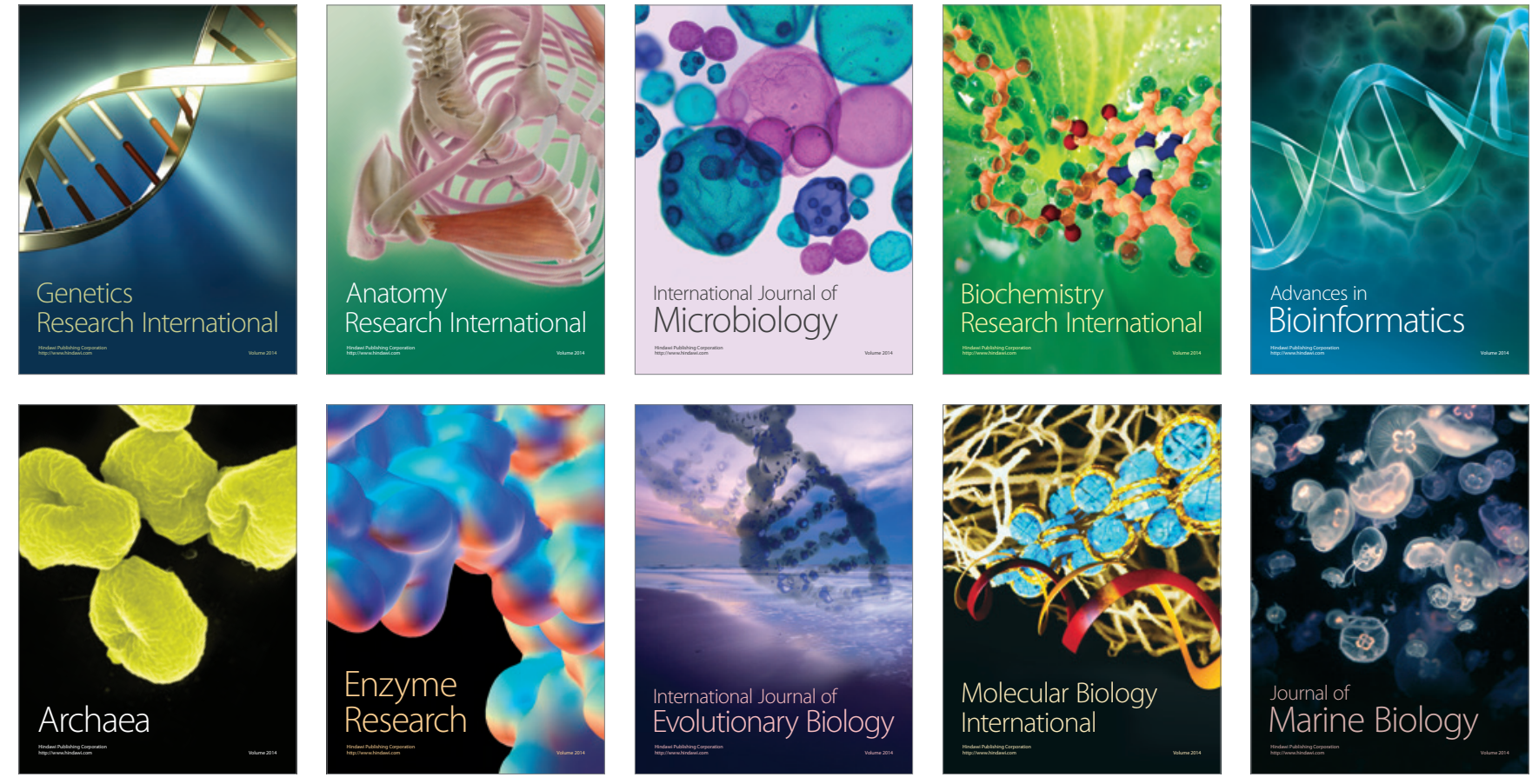